\title{
Evidence for heme release in layer-by-layer assemblies of myoglobin and polystyrenesulfonate on pyrolitic graphite
}

\author{
Matheus T. de Groot • Maarten Merkx • \\ Marc T. M. Koper
}

Received: 19 December 2006/Accepted: 12 March 2007/Published online: 5 April 2007

(C) SBIC 2007

\begin{abstract}
Layer-by-layer assemblies of myoglobin and polystyrenesulfonate (PSS) on pyrolitic graphite have been investigated with the goal of determining the origin of the voltammetric response of these films. From the similar midpoint potential, coverage and electron transfer behavior compared with those of adsorbed free heme, it was concluded that the observed voltammetric peak is due to heme adsorbed at the electrode surface. This suggests that the interactions between the pyrolitic graphite electrode, PSS and myoglobin can result in heme release from the protein followed by heme adsorption on the electrode.
\end{abstract}

Keywords Electrochemistry · Heme .

Electron transfer · Voltammetry · Denaturant

\section{Introduction}

The immobilization of redox proteins on electrodes is a topic of active research both for obtaining a better mecha-

M. T. de Groot $(\square)$

Laboratory of Inorganic Chemistry and Catalysis,

Schuit Institute of Catalysis,

P.O. Box 513, 5600 MB Eindhoven, The Netherlands

e-mail: m.t.d.groot@tue.nl

\section{Merkx}

Laboratory of Macromolecular and Organic Chemistry, Department of Biomedical Engineering,

Eindhoven University of Technology,

P.O. Box 513, 5600 MB Eindhoven, The Netherlands

M. T. de Groot - M. T. M. Koper

Leiden Institute of Chemistry,

Leiden University,

P.O. Box 9502, 2300 RA Leiden, The Netherlands nistic understanding of enzyme catalysis [1] and for the development of biosensors [2]. However, for the successful immobilization of a redox protein certain challenges have to be overcome. Firstly, the interactions between the protein and the electrode should be sufficient for immobilization, but should not significantly affect the tertiary structure of the protein. Secondly, in order to obtain electron transfer between the electrode and the redox group of the protein, the distance between them should not be much greater than $14 \AA$, the maximum observed for electron transfer between two redox centers in proteins [3]. To overcome these challenges, a wide variety of methods using covalent, electrostatic or hydrophobic interactions on numerous electrode materials, including gold, silver, indium oxide and pyrolitic graphite, have been investigated [4].

The extent to which an immobilization method affects the protein's properties can be probed in different ways. On gold, silver and indium oxide electrodes spectroscopic techniques such as surface-enhanced resonance Raman spectroscopy (SERRS) [5] and surface-enhanced infrared difference adsorption spectroscopy (SEIDAS) can be employed [6]. With these techniques it has, e.g., been shown that cytochrome $c$ retains a near-native conformation on carboxylic acid terminated self-assembled monolayers [7], whereas it undergoes significant conformational changes on bare metal electrodes [5, 8, 9]. On "dark" materials such as graphite spectroscopic measurements are difficult and therefore one has to rely largely on indirect electrochemical evidence. This includes the comparison of properties such as midpoint potential and enzymatic activity with those of the protein in solution [10-12] and the determination of whether the observed coverage and electron transfer behavior are typical of a protein [13, 14]. Using this kind of indirect evidence, we have shown that myoglobin $(\mathrm{Mb})$ in films of didodecyldimethylammonium 
bromide (DDAB) on pyrolitic graphite can undergo heme release under certain conditions [15, 16], although our conclusions were disputed by Guto and Rusling [17]. Another case in which partial or complete heme removal from $\mathrm{Mb}$ has been suggested is for $\mathrm{Mb}$ in agarose hydrogel films in ionic liquids [18].

In the present work we investigated layer-by-layer assemblies [19] of $\mathrm{Mb}$ and polystyrenesulfonate (PSS) on pyrolitic graphite [20]. It has been claimed that there is fast direct electron transfer between the electrode and the protein molecules in these assemblies and therefore these assemblies are interesting for mechanistic studies of redox enzymes and for use as biosensors. They can be made by alternately adsorbing negatively charged PSS and positively charged $\mathrm{Mb}$ [21-25]. Our goal was to determine whether the observed electrochemical response of these assemblies is due to the native protein or to a partially or completely denatured protein. We did this by comparing the electrochemical properties of the immobilized $\mathrm{Mb}$ with the properties of $\mathrm{Mb}$ in solution and of immobilized heme, a possible denaturation product.

\section{Materials and methods}

\section{Materials}

Horse heart $\mathrm{Mb}$ (purity better than $90 \%$, Aldrich), poly (sodium styrenesulfonate) (molecular weight approximately 70,000, Aldrich), poly(diallyldimethylammonium chloride) (PDDA; molecular weight approximately 200,000-350,000, Aldrich) and hemin (98\%, Fluka) were used as received. All other chemicals were pro analysi grade. Buffer solutions were prepared with sodium acetate (pH 5.5), sodium dihydrogen phosphate monohydrate $(\mathrm{pH}$ 6-8) and boric acid ( $\mathrm{pH} 9-10)$ combined with concentrated solutions of hydrochloric acid or sodium hydroxide and Millipore Milli-Q water (resistivity more than $18.2 \mathrm{M} \Omega \mathrm{cm}$ ). The concentration of the buffer was $0.1 \mathrm{M}$ in all experiments, except for the electron transfer rate constant experiments, where the buffer concentration was 3.0 M. Pyrolitic graphite (Carbone-Lorraine) was fabricated into homemade rotating ring-disk electrodes [26, 27]. The geometric surface area of the electrodes was $0.5 \mathrm{~cm}^{2}$. In the electron transfer rate constant experiments the surface area of the electrode was reduced by taping off part of the surface, in order to reduce the ohmic drop.

Electrochemical apparatus and procedures

An Autolab PGstat 20 potentiostat was used for cyclic voltammetry. A homemade three-electrode cell consisting of a platinum flag counter electrode, a $\mathrm{Hg} \mid \mathrm{Hg}_{2} \mathrm{SO}_{4}$ reference electrode and a pyrolitic graphite rotating-disk working electrode was employed. All potentials in this paper are relative to the standard hydrogen electrode (SHE). All solutions were deaerated by purging them with argon for $15 \mathrm{~min}$. All electrochemical experiments were performed at room temperature.

Preparation of $\{\mathrm{Mb}-\mathrm{PSS}\}_{n}$ multilayer on pyrolitic graphite

Prior to use, the pyrolitic graphite electrode was abraded using P1000 SiC sandpaper and ultrasonicated in Millipore Milli-Q water for $1 \mathrm{~min}$. The electrode was dried in a $\mathrm{N}_{2}$ stream for $5 \mathrm{~s}$. Subsequently, the electrode was immersed in $120 \mu \mathrm{M} \mathrm{Mb}$ in a $0.1 \mathrm{M}$ acetate solution, $\mathrm{pH} 5.5$, for 10 min. After being washed with water, the electrode was immersed in $3 \mathrm{mg} \mathrm{ml}^{-1} \mathrm{PSS}$ in a $0.1 \mathrm{M}$ acetate solution, $\mathrm{pH} 5.5$, containing $0.5 \mathrm{M} \mathrm{NaCl}$ for $10 \mathrm{~min}$. This cycle was repeated to make multilayer assemblies.

Preparation of adsorbed heme on pyrolitic graphite

A $0.5 \mathrm{mM}$ hemin solution was prepared by dissolving $1.6 \mathrm{mg}$ hemin in $5 \mathrm{ml}$ of a $0.01 \mathrm{M}$ borate solution, $\mathrm{pH} 11$, since hemin only dissolves in alkaline solution. Prior to use, the pyrolitic graphite electrode was abraded using P1000 SiC sandpaper and ultrasonicated in Millipore Milli$\mathrm{Q}$ water for $1 \mathrm{~min}$. The electrode was dried in a $\mathrm{N}_{2}$ stream for $5 \mathrm{~s}$. The electrode was immersed in the hemin solution for $10 \mathrm{~min}$ to saturate the surface with hemin [28, 29], after which the electrode was rinsed with water.

Preparation of a PDDA-PSS-heme-PDDA-PSS layer on pyrolitic graphite

Prior to use, the pyrolitic graphite electrode was abraded using P1000 SiC sandpaper and ultrasonicated in Millipore Milli-Q water for $1 \mathrm{~min}$. The electrode was immersed in $3 \mathrm{mg} \mathrm{ml}^{-1}$ PDDA in $0.1 \mathrm{M}$ acetate solution, $\mathrm{pH}$ 5.5, containing $0.5 \mathrm{M} \mathrm{NaCl}$ for $10 \mathrm{~min}$. After being washed with water, the electrode was immersed in a $3 \mathrm{mg} \mathrm{ml}^{-1}$ PSS $0.1 \mathrm{M}$ acetate solution, $\mathrm{pH} 5.5$, containing $0.5 \mathrm{M} \mathrm{NaCl}$ for $10 \mathrm{~min}$. Subsequently, the electrode was immersed in a $0.5 \mathrm{mM}$ hemin $0.01 \mathrm{M}$ borate solution, $\mathrm{pH} \mathrm{11,} \mathrm{for} 30 \mathrm{~min}$. This was followed by 10-min immersion in the PDDA solution and 10-min immersion in the PSS solution.

\section{Results}

Figure 1 shows the voltammetric response of a layer-bylayer assembly of PSS and Mb on pyrolitic graphite, which was made by alternately adsorbing negatively charged PSS 
and positively charged $\mathrm{Mb}$, both buffered at $\mathrm{pH}$ 5.5. The voltammetric peak corresponds to the $\mathrm{Fe}^{\mathrm{III}} / \mathrm{Fe}^{\mathrm{II}}$ redox transition of the protein's heme group. The charge under the voltammetric peaks increases with the number of layers, corresponding to a coverage of approximately $2.6 \times 10^{-10} \mathrm{~mol} \mathrm{~cm}^{-2}$ for a $\{\mathrm{Mb}-\mathrm{PSS}\}_{6}$ multilayer. The midpoint potential is $-0.04 \pm 0.01 \mathrm{~V}$ versus SHE and the peak separation is $120 \pm 10 \mathrm{mV}$. All these properties are in reasonable agreement with results in the literature [24] and show that we have prepared similar films.

The midpoint potential determined significantly differs from the midpoint potential of $\mathrm{Mb}$ in solution, which is $0.06 \mathrm{~V}$ versus SHE at $\mathrm{pH} 5.5[30,31]$. This could be related to either a change in the heme environment of the protein or a local electric field, as has been reported for cytochrome $c$ immobilized on carboxylic acid terminated self-assembled monolayers [32-35]. To obtain more insight into the effect of the immobilization, we determined the midpoint potential over a broad $\mathrm{pH}$ range and compared it with that of $\mathrm{Mb}$ in solution (Fig. 2). Figure 2 reveals differences between immobilized $\mathrm{Mb}$ and $\mathrm{Mb}$ in solution of more than $250 \mathrm{mV}$ above $\mathrm{pH}$ 9. This is significantly more than the maximum shift of $70 \mathrm{mV}$ reported between immobilized cytochrome $c$ and cytochrome $c$ in solution. It is unlikely that such a large shift is solely due to an electric field, suggesting that at least part of the difference is due to an altered heme environment.

In previous studies on $\mathrm{Mb}-\mathrm{DDAB}$ films on pyrolitic graphite we discovered that heme release can occur in these films, and that the observed electrochemical response was in fact due to isolated heme $[15,16]$. To determine whether a similar process occurs in the $\{\mathrm{Mb}-\mathrm{PSS}\}_{6}$ multilayer film, we compared the voltammetric response of the multilayer

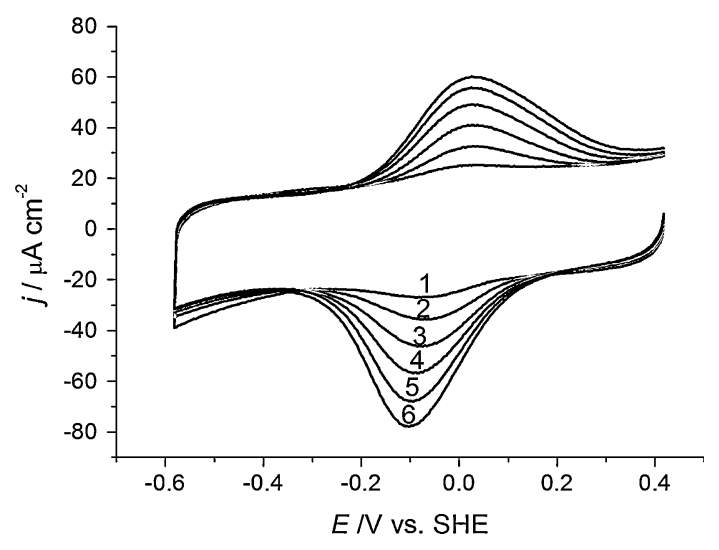

Fig. 1 Cyclic voltammograms of a pyrolitic graphite electrode after alternate adsorption from a $120 \mu \mathrm{M}$ myoglobin $(\mathrm{Mb})$ solution and a $3 \mathrm{mg} \mathrm{ml}^{-1}$ polystyrenesulfonate (PSS) solution, both buffered at $\mathrm{pH}$ 5.5. Voltammetry at a scan rate of $500 \mathrm{mV} \mathrm{s}^{-1}$ was performed in $0.1 \mathrm{M}$ acetate, $\mathrm{pH}$ 5.5. The number of Mb-PSS layers is indicated by 1-6. SHE standard hydrogen electrode film with that of adsorbed hemin at pH 5.5 (Fig. 3) and with that of heme in a film of positively and negatively charged polymers. Direct comparison with a heme-PSS film is not possible, since the negatively charged PSS only adsorbs on the electrode when there is an electrostatic interaction with a positively charged polymer such as $\mathrm{Mb}$. Figure 3 shows similarities and differences between the $\{\mathrm{Mb}-\mathrm{PSS}\}_{6}$ multilayer and adsorbed heme. The coverage $\left(4.0 \times 10^{-10} \mathrm{~mol} \mathrm{~cm}^{-2}\right)$ and midpoint potential $(-0.03 \pm 0.01 \mathrm{~V}$ vs. SHE) of adsorbed heme are comparable with those of a $\{\mathrm{Mb}-\mathrm{PSS}\}_{6}$ multilayer. Especially the latter is striking, since the midpoint potential is determined by the heme environment and this is significantly different in adsorbed heme compared with $\mathrm{Mb}$. To further investigate this similarity, we determined the midpoint potentials of both films over the $\mathrm{pH}$ 5-10 range (Fig. 2). A very close correspondence was found, which suggests that the voltammetric response of the $\{\mathrm{Mb}-\mathrm{PSS}\}_{6}$ multilayer is caused by an electroactive group that closely resembles adsorbed heme. However, Fig. 3 also shows a distinctly different peak shape and lower peak separation $(20 \mathrm{mV})$ for adsorbed heme than for the $\{\mathrm{Mb}-\mathrm{PSS}\}_{6}$ multilayer. To determine whether this might be related to the presence of PSS in the $\{\mathrm{Mb}-\mathrm{PSS}\}_{6}$ multilayer, we incorporated heme in a multilayer of positively charged PDDA and negatively charged PSS. It appeared that the presence of both charged polymers induces a peak separation of $115 \mathrm{mV}$, which is comparable to the peak separation of $120 \mathrm{mV}$ observed for a $\{\mathrm{Mb}-\mathrm{PSS}\}_{6}$ multilayer. This suggests that the presence of PSS can indeed cause an increased peak separation. The PDDA-PSS multilayer also induces a $30-\mathrm{mV}$ shift in midpoint potential compared with adsorbed heme. Nevertheless, the $\mathrm{pH}$ dependence of the midpoint potential of heme incorporated in the PDDA-PSS multilayer is comparable to that of adsorbed heme (data not shown).

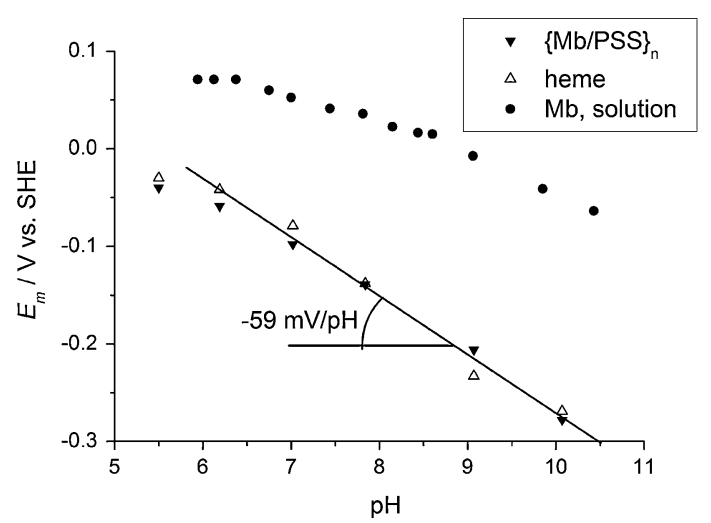

Fig. 2 Midpoint potentials of a $\{\mathrm{Mb}-\mathrm{PSS}\}_{6}$ multilayer film on pyrolitic graphite (filled triangles) as a function of $\mathrm{pH}$ compared with those of Mb in solution (circles) [30] and adsorbed hemin on pyrolitic graphite (open triangles). Buffer $0.1 \mathrm{M}$ acetate, phosphate or borate; scan rate $500 \mathrm{mV} \mathrm{s}^{-1}$ 


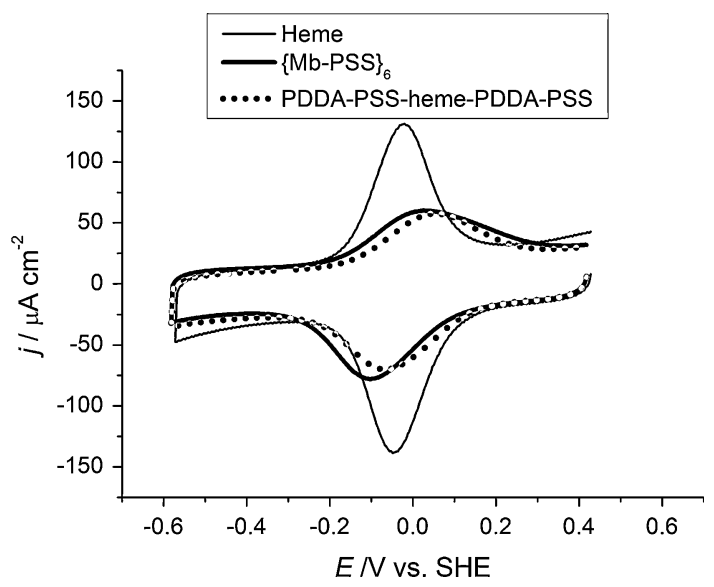

Fig. 3 Cyclic voltammograms of adsorbed heme (thin line), a $\{\mathrm{Mb}-$ PSS $\}_{6}$ multilayer (thick line) and a PDDA-PSS-heme-PDDA-PSS layer (dotted line) on pyrolitic graphite. Voltammetry at a scan rate of $500 \mathrm{mV} \mathrm{s}^{-1}$ was performed in $0.1 \mathrm{M}$ acetate, $\mathrm{pH}$ 5.5. PDDA poly(diallyldimethylammonium chloride)

To learn more about the properties of a $\{\mathrm{Mb}-\mathrm{PSS}\}_{6}$ multilayer, we tried to determine the electron transfer rate constant between the electrode and the heme group. This was done by measuring voltammograms at increasing scan rates. The anodic and cathodic peak potentials should start to shift with increasing scan rate, since the electron transfer cannot "keep up" with the high scan rate. From the dependence of peak separation on scan rate it is possible to calculate the electron transfer rate constants by employing Laviron's theory [36]. However, Fig. 4 shows that in the case of a $\{\mathrm{Mb}-\mathrm{PSS}\}_{6}$ multilayer, the peak separation does not shift with increasing scan rates. At $50 \mathrm{~V} \mathrm{~s}^{-1}$ the peak separation is still the same as at $500 \mathrm{mV} \mathrm{s}^{-1}$, namely, $130 \mathrm{mV}$. Measuring at higher scan rates is possible, but owing to a significant ohmic drop it becomes difficult to accurately determine the peak potentials; therefore, we were unable to determine the exact electron transfer rate constant. However, on the basis of the fact that no significant increase in peak separation is observed at $50 \mathrm{~V} \mathrm{~s}^{-1}$, we can deduce that the electron transfer rate constant is at least $500 \mathrm{~s}^{-1}$. Such a high electron transfer rate constant is not expected for a multilayer system where the large size of the $\mathrm{Mb}$ molecules implies that electrons have to tunnel over long distances in order to enable electron transfer between two protein molecules. Also, direct electron transfer between the electrode and the outer protein layers at this high rate seems unlikely, since the distance well exceeds $14 \AA$, the maximum for fast electron transfer between two redox centers in proteins [3]. Moreover, one would expect diffusion-controlled behavior, similar to what has been observed for layer-by-layer assemblies of cytochrome $c$ and poly(anilinesulfonic) acid [37, 38]. Therefore, it seems more likely that the electroactive response is caused by a redox-active group which is close to the electrode, possibly

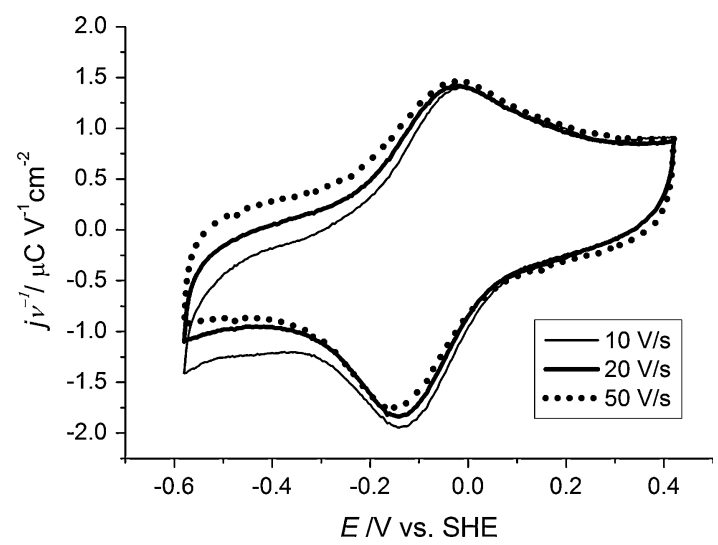

Fig. 4 Cyclic voltammograms of a $\{\mathrm{Mb}-\mathrm{PSS}\}_{6}$ multilayer on pyrolitic graphite in $3.0 \mathrm{M}$ acetate, $\mathrm{pH} 5.5$, at $10 \mathrm{~V} \mathrm{~s}^{-1}$ (thin line), $20 \mathrm{~V} \mathrm{~s}^{-1}$ (thick line) and $50 \mathrm{~V} \mathrm{~s}^{-1}$ (dotted line). Measured currents were divided by the scan rate to allow for comparison between different scan rates

adsorbed heme. We tried to determine the electron transfer rate constant for adsorbed heme, but similar to the

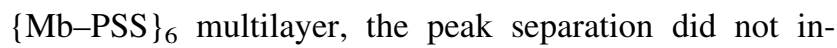
crease with increasing scan rate up to $50 \mathrm{~V} \mathrm{~s}^{-1}$ (data not shown). This implies that the electron transfer rate constant again exceeds $500 \mathrm{~s}^{-1}$. This agrees with a previous study for heme adsorbed on glassy carbon, in which a rate constant of $4.9 \times 10^{3} \mathrm{~s}^{-1}$ was found by employing potential-modulated UV-vis reflectance spectroscopy [39]. The similarity between the $\{\mathrm{Mb}-\mathrm{PSS}\}_{6}$ multilayer and adsorbed heme again suggests that part of the $\mathrm{Mb}$ in the multilayer system undergoes heme release, which is followed by subsequent heme adsorption.

Although the poor reflection of the pyrolitic graphite electrode makes it difficult to do spectroscopy, one can gain interesting information by simple visible inspection. During the layer-by-layer formation, the color of the electrode becomes more brownish as can be seen in Fig. 5 . This is due to the combination of multiple Mb layers which adsorb visible light. The darkening can therefore be used as a crude tool to determine whether the $\{\mathrm{Mb}-\mathrm{PSS}\}_{n}$ multilayer formation indeed occurs. In contrast, no significant darkening is observed when free heme is adsorbed on the electrode, since the monolayer coverage is too low to be visually observed.

Interestingly, when a $\{\mathrm{Mb}-\mathrm{PSS}\}_{6}$ multilayer electrode is immersed in a $0.1 \mathrm{M}$ borate solution of $\mathrm{pH} 9$ for $10 \mathrm{~min}$, the brownish color disappears from the electrode (Fig. 5). This indicates that the multilayer is desorbed from the electrode, which can be explained by the fact that at $\mathrm{pH} 9$ $\mathrm{Mb}$ becomes negatively charged $(\mathrm{pI}=7.35)[40]$ and hence the electrostatic interaction with the negatively charged PSS becomes repulsive. If the voltammetric response were due to the $\mathrm{Mb}$ in the multilayer, one would expect that this 


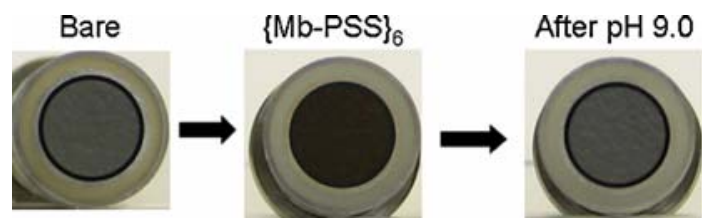

Fig. 5 Photographs of the pyrolitic graphite electrode before and after a $\{\mathrm{Mb}-\mathrm{PSS}\}_{6}$ multilayer has formed on the electrode. A photograph of the electrode after a $10-$ min immersion in a $0.1 \mathrm{M} \mathrm{pH} 9$ borate solution is also shown

would also result in the disappearance of the voltammetric peaks. However, Fig. 6, which shows the voltammetric response after immersion in a $\mathrm{pH} 9.0$ solution and subsequent reimmersion in a $\mathrm{pH} 5.5$ solution, shows that this is not the case. The coverage decreases, but large voltammetric peaks remain. This is an indication that the voltammetric response is not due to $\mathrm{Mb}$ in the Mb-PSS multilayer, but instead is due to a redox-active group close to the electrode, of which only a small fraction is desorbed from the electrode when the $\mathrm{pH}$ is increased. Heme that is either directly adsorbed on the electrode or embedded in the first layer of PSS is the most likely candidate for this redox-active group. It is interesting to see that the peak separation decreased to $70 \mathrm{mV}$ in the second measurement at $\mathrm{pH}$ 5.5. Probably, this is related to the fact that a large fraction of the PSS polymer desorbed from the electrode, and hence the peak separation caused by this polymer decreases.

Our heme-release hypothesis would imply that free heme is formed by interactions between PSS, Mb and pyrolitic graphite. This suggests that it should be possible to obtain a voltammetric response by immersing the electrode in a mixture of PSS and $\mathrm{Mb}$, and that formation of a

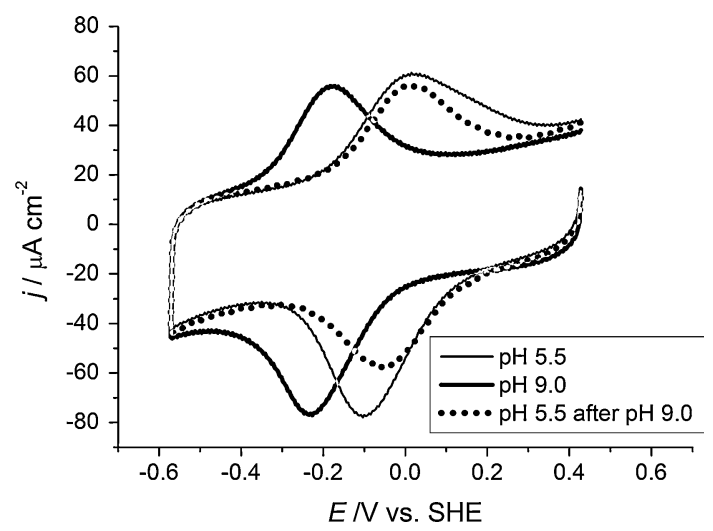

Fig. 6 Cyclic voltammograms of a $\{\mathrm{Mb}-\mathrm{PSS}\}_{6}$ multilayer on pyrolitic graphite in a $0.1 \mathrm{M} \mathrm{pH} 5.5$ acetate solution (thin line) and in a $0.1 \mathrm{M} \mathrm{pH} 9.0$ borate solution (thick line). The voltammetric scan that is obtained after reimmersion in a $0.1 \mathrm{M} \mathrm{pH} 5.5$ acetate solution is also plotted (dotted line). Scan rate $500 \mathrm{mV} \mathrm{s}^{-1}$ multilayer by alternate adsorption of PSS and $\mathrm{Mb}$ is not necessary. Figure 7 shows that immersion in a Mb-PSS mixture indeed results in a large voltammetric peak, which is found at the same potential as for a $\{\mathrm{Mb}-\mathrm{PSS}\}_{6}$ multilayer and also has a similar shape. Apart from the midpoint potential, the Mb-PSS mixture film also has a coverage $\left(4.0 \times 10^{-10} \mathrm{~mol} \mathrm{~cm}^{-2}\right)$ that is comparable to the coverage of adsorbed heme. One could argue that it is possible to directly adsorb a multilayer or mixture of $\mathrm{Mb}$ and PSS from this solution, but this seems unlikely since there are no interactions that favor adsorption in this case. Also, the electrode does not undergo a significant darkening after immersion in the Mb-PSS mixture, whereas one would expect a darkening comparable to that of a $\{\mathrm{Mb}-\mathrm{PSS}\}_{6}$ multilayer (Fig. 5), if a thick Mb-PSS film had adsorbed. Therefore, it seems more likely that the voltammetric response is due to free heme.

\section{Discussion and conclusions}

Our results indicate that the voltammetric response of a $\{\mathrm{Mb}-\mathrm{PSS}\}_{n}$ multilayer on pyrolitic graphite can be ascribed to free heme, which is either directly adsorbed on the electrode or embedded in the PSS layer. We base this on (1) the large difference in midpoint potential of a $\{\mathrm{Mb}-\mathrm{PSS}\}_{n}$ multilayer on pyrolitic graphite compared with that of $\mathrm{Mb}$ in solution, (2) the similar $\mathrm{pH}$ dependence of the midpoint potential of a $\{\mathrm{Mb}-\mathrm{PSS}\}_{n}$ multilayer on pyrolitic graphite and adsorbed heme, (3) the similar coverage of a $\{\mathrm{Mb}-\mathrm{PSS}\}_{6}$ multilayer on pyrolitic graphite and adsorbed heme (4) the similar peak separation of a $\{\mathrm{Mb}-\mathrm{PSS}\}_{6}$ multilayer and a PDDA-PSS-heme-PDDA-PSS film, (5)

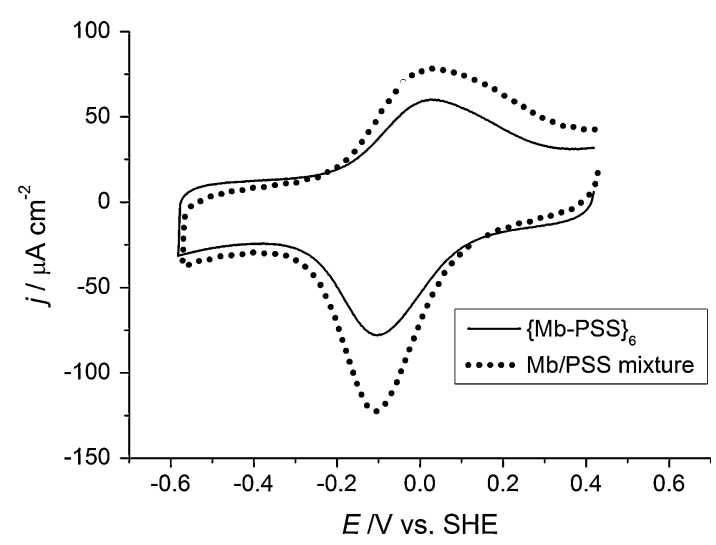

Fig. 7 Cyclic voltammograms of a $\{\mathrm{Mb}-\mathrm{PSS}\}_{6}$ multilayer (thin line) and a Mb-PSS mixture (dotted line) on pyrolitic graphite. Voltammetry at a scan rate of $500 \mathrm{mV} \mathrm{s}^{-1}$ was performed in $0.1 \mathrm{M}$ acetate, $\mathrm{pH}$ 5.5. The Mb-PSS mixture film was made by immersing a freshly sanded pyrolitic graphite electrode in a solution of $60 \mu \mathrm{M} \mathrm{Mb}$ and $1.5 \mathrm{mg} \mathrm{ml}^{-1}$ PSS in $0.05 \mathrm{M} \mathrm{pH} 5.5$ acetate solution with $0.25 \mathrm{M}$ $\mathrm{NaCl}$ for $3 \mathrm{~h}$ 
the high electron transfer rate constants of a $\{\mathrm{Mb}-\mathrm{PSS}\}_{n}$ multilayer, which is unlikely for electron transfer to protein molecules, but is in line with the electron transfer expected for a layer of adsorbed heme, (6) the fact that desorption of the multilayer induced by high $\mathrm{pH}$ does not result in the disappearance of the voltammetric peaks and (7) the fact that a large voltammetric response can be obtained by direct immersion in a Mb-PSS mixture, showing that the formation of multilayers is not necessary.

Our conclusion is in apparent disagreement with previous studies on $\{\mathrm{Mb}-\mathrm{PSS}\}_{n}$ layer-by-layer films on pyrolitic graphite [22-25], in which it was concluded that Mb retains a near-native conformation in the layer-by-layer films. This was concluded mainly on the basis of spectroscopic data, which consistently show that $\mathrm{Mb}$ retains a near-native conformation. However, these spectroscopic measurements were carried out on $\{\mathrm{Mb}-\mathrm{PSS}\}_{n}$ multilayers on transparent or reflective surfaces and not on pyrolitic graphite. Therefore they fail to take into account possible specific interactions between the pyrolitic graphite electrode, PSS and $\mathrm{Mb}$. As we reported for Mb-DDAB films these interactions with the electrode can sometimes enhance heme release $[15,16]$. The spectroscopic data therefore only show that $\mathrm{Mb}$ retains a near-native conformation in the absence of interactions with the electrode, corresponding to the $\mathrm{Mb}$ present in the layers far away from the electrode. On the other hand, our voltammetric results are a measure of the state of the protein near the electrode. Hence, the spectroscopic data are not in disagreement with our conclusion that heme release followed by heme adsorption can occur in $\{\mathrm{Mb}-\mathrm{PSS}\}_{n}$ multilayers on pyrolitic graphite. We therefore emphasize that we do not claim that all $\mathrm{Mb}$ molecules in the layer-by-layer assembly undergo heme release. Only a small fraction near the pyrolitic graphite electrode may be involved, but it is this small fraction that nevertheless determines the electrochemical response of the assembly.

Acknowledgement This work was supported by the National Research School Combination Catalysis (NRSC-C).

\section{References}

1. Armstrong FA (2002) J Chem Soc Dalton Trans 661-671

2. Schuhmann W (2002) Rev Mol Biol 82:425

3. Page CC, Moser CC, Chen X, Dutton PL (1999) Nature 402:47

4. Armstrong FA, Wilson GS (2000) Electrochim Acta 45:26232645
5. Hildebrandt $P$, Stockburger M (1989) Biochemistry 28:6710

6. Ataka K, Heberle J (2004) J Am Chem Soc 126:9445

7. Hildebrandt P, Murgida DH (2002) Bioelectrochemistry 55:139

8. Hobara D, Niki K, Cotton TM (1998) Biospectroscopy 4:161

9. Wackerbarth H, Hildebrandt P (2003) ChemPhysChem 4:714-724

10. Elliott SJ, Hoke KR, Heffron K, Palak M, Rothery RA, Weiner JH, Armstrong FA (2004) Biochemistry 43:799

11. Hudson JM, Heffron K, Kotlyar V, Sher Y, Maklashina E, Cecchini G, Armstrong FA (2005) J Am Chem Soc 127:6977

12. Vincent KA, Parkin A, Lenz O, Albracht SPJ, Fontecilla-Camps JC, Cammack R, Friedrich B, Armstrong FA (2005) J Am Chem Soc 127:18179

13. de Groot MT, Evers TH, Merkx M, Koper MTM (2007) Langmuir 23:729-736

14. Armstrong FA, Camba R, Heering HA, Hirst J, Jeuken LJC, Jones AK, Leger C, McEvoy JP (2000) Faraday Discuss 116:191

15. de Groot MT, Merkx M, Koper MTM (2006) Electrochem Commum 8:999

16. de Groot MT, Merkx M, Koper MTM (2005) J Am Chem Soc 127:16224

17. Guto PM, Rusling JF (2006) Electrochem Commun 8:455-459

18. Brusova Z, Gorton L, Magner E (2006) Langmuir 22:1145311455

19. Decher G (1997) Science 277:1232-1237

20. Rusling JF, Forster RJ (2003) J Colloid Interface Sci 262:1-15

21. Lvov Y, Ariga K, Ichinose I, Kunitake T (1995) J Am Chem Soc 117:6117-6123

22. Lvov Y, Ariga K, Kunitake T (1994) Chem Lett 2323-2326

23. Lvov YM, Lu Z, Schenkman JB, Zu X, Rusling JF (1998) J Am Chem Soc 120:4073-4080

24. Ma H, Hu N, Rusling JF (2000) Langmuir 16:4969-4975

25. Panchagnula V, Kumar CV, Rusling JF (2002) J Am Chem Soc 124:12515-12521

26. Van den Brink F, Visscher W, Barendrecht E (1983) J Electroanal Chem 157:283-304

27. Van der Plas JF, Barendrecht E (1977) Rec Trav Chim Pays Bas 96:133-136

28. Brown AP, Koval C, Anson FC (1976) J Electroanal Chem 72:379-387

29. Duong B, Arechabaleta R, Tao NJ (1998) J Electroanal Chem 447:63-69

30. Behlke J, Scheler W (1961) Naturwissenschaften 48:717

31. Brunori M, Saggese U, Rotilio GC, Antonini E, Wyman J (1971) Biochemistry 10:1604-1609

32. Murgida DH, Hildebrandt P (2004) Acc Chem Res 37:854-861

33. de Groot MT, Merkx M, Koper MTM (2007) Langmuir 23:38323839

34. Petrovic J, Clark RA, Yue H, Waldeck DH, Bowden EF (2005) Langmuir 21:6308

35. Fedurco M (2000) Coord Chem Rev 209:263-331

36. Laviron E (1979) J Electroanal Chem 101:19

37. Beissenhirtz MK, Kafka J, Schaefer D, Wolny M, Lisdat F (2005) Electroanalysis 17:1931-1937

38. Beissenhirtz MK, Scheller FW, Stocklein WFM, Kurth DG, Mohwald H, Lisdat F (2004) Angew Chem Int Ed Engl 43:43574360

39. Feng ZQ, Sagara T, Niki K (1995) Anal Chem 67:3564-3570

40. Radola BJ (1973) Biochim Biophys Acta 295:412-428 